\title{
Implementation of fibre-optic vertical extensometers for safety monitoring
}

\author{
C Rabaiotti Basler \& Hofmann AG, Switzerland \\ M Iten Marmota Engineering AG, Switzerland \\ F Fischli Marmota Engineering AG, Switzerland
}

\begin{abstract}
The Westlink is one of the major city development projects of the Swiss federal railway company (SBB CFF FFS) in Zürich: three tall office buildings (total 70,000 $\mathrm{m}^{2}$ for office, flats and shops) have been recently constructed in close proximity to the railway tracks. An existing water pipeline of $2.1 \mathrm{~m}$ in diameter is running below the buildings at a depth of $10 \mathrm{~m}$. The pipeline is an important component within the city's water supply system with an internal pressure of 10 bar.

To assure the pipeline safety and integrity, an assessment of the tolerable pipeline displacement during construction was carried out and monitoring was implemented. The assessment consisted of modelling the depth-dependent soil deformation during construction using a three-dimensional finite element modelling. The modelling allowed predicted settlement and allowed definition of critical values for the safety of the pipeline. Subsequently, implementation of a sophisticated monitoring system based on fibre-optic sensors and conventional geotechnical monitoring methods was carried out. Thus, the combination of advanced modelling and monitoring allowed reliable risk assessment for the pipeline and the building through all the construction phases.
\end{abstract}

\section{$1 \quad$ Introduction}

The city of Zürich in Switzerland is expanding its downtown to the former industrial district of Zürich West. Many companies are moving their headquarters into this part of the city that was previously dominated by industry. The new buildings are therefore going to be constructed on an already heavily built underground: in particular important pipelines lay beneath the future buildings and should not be damaged during construction. The large building complex Westlink, also located in this district, is being built in a strategic location near the Altstetten railway station (Figure 1).

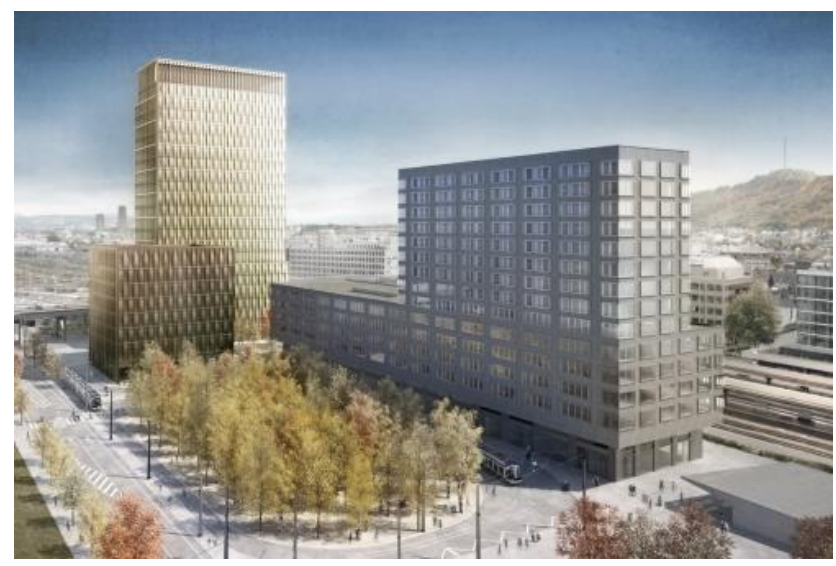

Figure 1 Rendering of the Westlink buildings in Zürich

One of the most important drinking water pipelines runs approximately $10 \mathrm{~m}$ below the new building. In order to assess if the additional load from the buildings is could damage the pipeline, settlement analyses 
were carried out by the Swiss federal railway company (SBB). Additionally, the Zürich Drinkwater Authority (WVZ) commissioned the company Basler \& Hofmann AG for a detailed analysis regarding the pipeline safety during and after construction of the building and to supervise the works.

In order to supervise the construction activities, a reliable monitoring concept was requested by Basler \& Hofmann AG that was successively implemented by the SBB. The results of the modelling, the monitoring concepts, the measured settlements and validation of geotechnical parameters are described in this paper.

\section{Geology}

During the last glaciation, a large glacier covered the entire valley of the river Limmat in Zürich (Jäckli Geologie 2008). After the glacier melted, a large lake formed. This lake was later filled with sand and clay sediments. After the lake disappeared, the river covered the floor with gravel, the so called 'Limmat Schotter'. The sand and clay sediments are very stiff and probably partially overconsolidated due to the wandering of the glacier front. The type and thickness of soils on the site are described in Table 1.

Table 1 Geological characterisation at the construction site Westlink (Jäckli Geologie 2008)

\begin{tabular}{ccc}
\hline $\begin{array}{c}\text { Soil } \\
\text { (USCS classification) }\end{array}$ & $\begin{array}{c}\text { Thickness } \\
\text { (m) }\end{array}$ & $\begin{array}{c}\text { Altitude } \\
\text { (m. a. s. I.) }\end{array}$ \\
\hline Man-made sediments & 1.8 & 397.1 to 395.3 \\
Gravel-Sand (GP-SP) & 4.2 & 395.3 to 391.1 \\
Sand-Clay (SP-SC) & $>70 \mathrm{~m}$ & 391.1 to 320.0 \\
\hline
\end{tabular}

The geological-geotechnical site characterisation was obtained by inverse analysis of settlements induced during construction of a nearby highway bridge (Gysi Leoni Mader AG 2005). The geotechnical parameters are listed in Table 2.

Table 2 Geotechnical parameters for the soil at the construction site Westlink (Gysi Leoni Mader AG 2005)

\begin{tabular}{ccccc}
\hline $\begin{array}{c}\text { Soil } \\
\text { (USCS Classification) }\end{array}$ & $\begin{array}{c}\boldsymbol{v}^{\prime} \\
\left(\mathbf{k N} / \mathbf{m}^{\mathbf{3}}\right)\end{array}$ & $\begin{array}{c}\boldsymbol{\varphi}^{\prime} \\
\mathbf{(}^{\mathbf{0}}\end{array}$ & $\begin{array}{c}\mathbf{c}^{\prime} \\
\left(\mathbf{k N} / \mathbf{m}^{\mathbf{2}}\right)\end{array}$ & $\begin{array}{c}\mathbf{E}^{\prime} \\
\left(\mathbf{M N} / \mathbf{m}^{\mathbf{2}}\right)\end{array}$ \\
\hline Man-made sediments & 19 & 28 & 1 & 7 \\
Gravel-Sand (GP-SP) & 21 & 37 & 0 & 80 \\
Sand-Clay (SP-SC) & 20 & 30 & 0 & 100 \\
\hline
\end{tabular}

Unfortunately, the dimensions of the bridge foundation are rather small compared to the one of the future building. This means that the new building compared to the bridge is going to load the soil to a much deeper level. Later in the paper it will be shown that the soil characterisation based on inverse analysis of the bridge settlements is not reliable for predicting the settlements of the new foundation.

\section{$3 \quad 3 \mathrm{D}$ finite element analysis}

\subsection{Boundary conditions and adopted FE model}

A three-dimensional model of one relevant part of the building complex (Figure 2) is implemented in the FE program PLAXIS 3D Foundation (Brinkgreve et al. 2007) (Figure 3). This building part is constructed directly above the pipeline. In order to minimise the effects of the boundary conditions, the dimensions of the FE model are chosen three times larger than the correspondent foundation $x$-y lengths. Also, the model depth $z$ is chosen three times larger than the foundation length. The foundation slab of the building and the 
piles are modelled with shell and embedded pile elements. The building walls and roofs are modelled as an additional load (Figure 3).

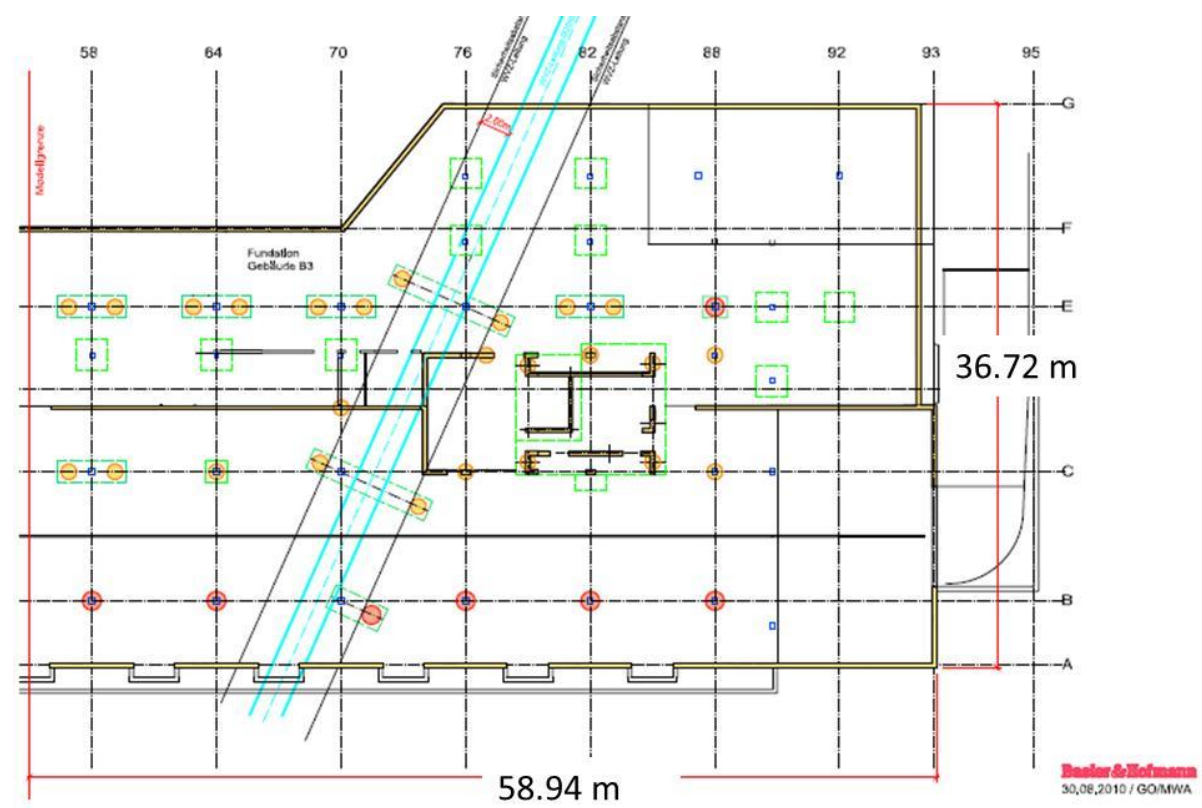

Figure 2 Layout of the foundation slab, piles and position of the pipeline (light blue)

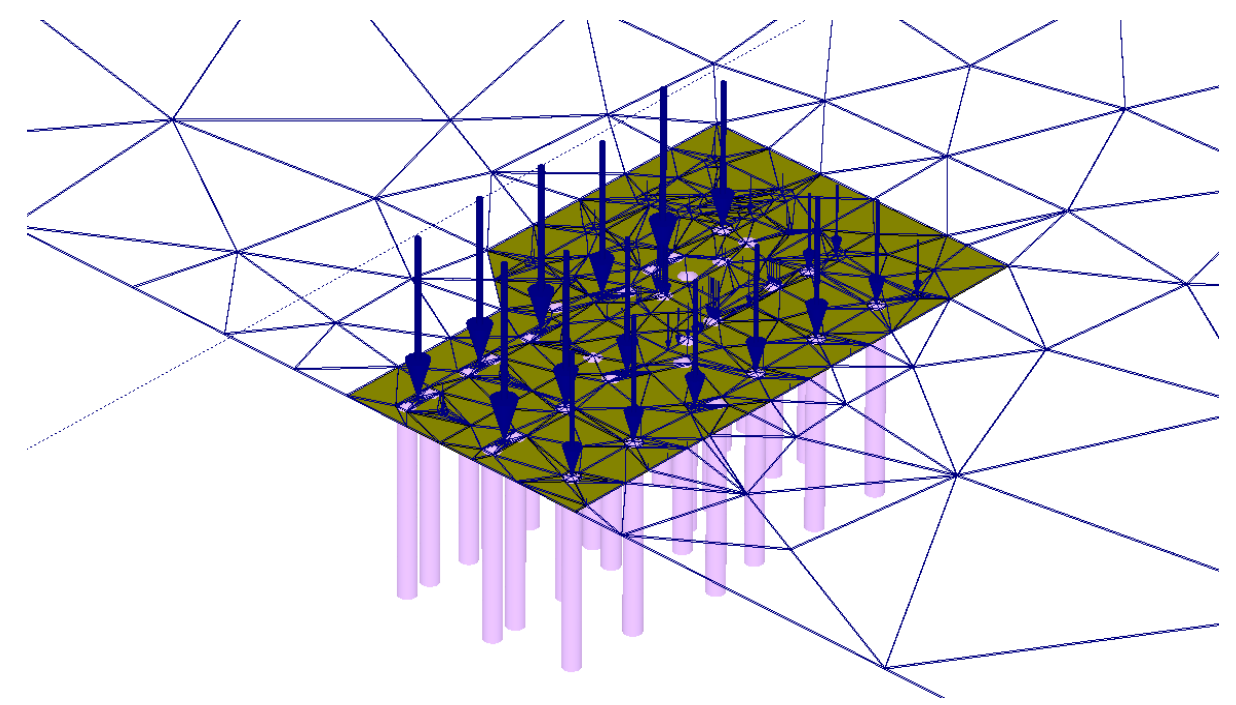

Figure 3 Three-dimensional FE model (PLAXIS ${ }_{3}$ D Foundation) of the pile foundation for the Westlink building

\subsection{Choice of constitutive model for the soil}

In a first analysis, the elasto-plastic strain hardening constitutive model (Hardening Soil small model, HSs) that is implemented in PLAXIS 3D Foundation was chosen. This constitutive model was developed in order to model the mechanical behaviour of a granular soil with a low degree of plasticity (Schanz et al. 1999; Benz 2007). The model allows in particular reproducing the stress and strain level dependent stiffness of soils and is widely adopted especially for practical applications.

In order to carry out a conservative prediction for the settlements of the pipeline, the higher stiffness of the soils (Burland 1989; Benz 2007) at small strains was neglected. It will be shown later, that for predicting correct settlements the small strain stiffness of soil, in particular of the deeper layers where the strains are very low, has to be taken into account. 
The pressure dependent stiffness parameters (for $p_{\text {ref }}=$ atmospheric pressure: $100 \mathrm{kPa}$ ) for the Hardening Soil constitutive model (the small strain stiffness is not taken into account) are listed in Table 3.

Table 3 Hardening Soil model parameters for the soils at the construction site

\begin{tabular}{cccc}
\hline $\begin{array}{c}\text { Soil } \\
\text { (USCS Classification) }\end{array}$ & $\begin{array}{c}\mathbf{E}_{50}{ }^{\text {ref }} \\
\left(\mathbf{M N} / \mathbf{m}^{2}\right)\end{array}$ & $\begin{array}{c}\mathbf{E}_{\text {ur }} \text { ref } \\
\left(\mathbf{M N} / \mathbf{m}^{2}\right)\end{array}$ & $\begin{array}{c}\mathbf{M} \\
(-)\end{array}$ \\
\hline Gravel-sand (GP-SP) & 80 & 240 & 0.5 \\
Sand-clay (SP-SC) & 100 & 300 & 0.5 \\
\hline
\end{tabular}

\section{$4 \quad$ Settlements and critical values}

The pipeline itself could not be modelled with the PLAXIS 3D foundation software; therefore, only soil settlements at the depth of the pipeline were analysed.

In order to assess the influence of settlements on the safety of the pipeline, a finite element analysis of the pipeline structural elements is carried out with the FE program AXIS. The pipeline is made of interconnected concrete covered $4.5 \mathrm{~m}$ long steel cylinders; therefore, its critical point is represented by the welded connections. To analyse the pipeline safety, the tensions in the welded connections due to different settlement gradients were determined. Critical settlement gradients are determined according to the results of the PLAXIS 3D Foundation analysis (Table 4). The gradient is calculated as the highest value of the tangent to the curve between maximum and 0 settlement.

Table 4 Gradient of pipeline settlement, the predicted and the maximum tolerable value

\begin{tabular}{ccc}
\hline $\begin{array}{c}\text { Gradient of pipeline } \\
\text { settlement }\end{array}$ & $\begin{array}{c}\text { Maximum } \\
\text { gradient (total) }\end{array}$ & $\begin{array}{c}\text { Maximum gradient } \\
\text { (segment) }\end{array}$ \\
\hline Estimated & 0.00036 & 0.00012 \\
Maximum & & $0.00024^{*}$ \\
\hline * Factor of Safety $=2.0$ & &
\end{tabular}

In Figure 4 predicted pipeline settlements is plotted.

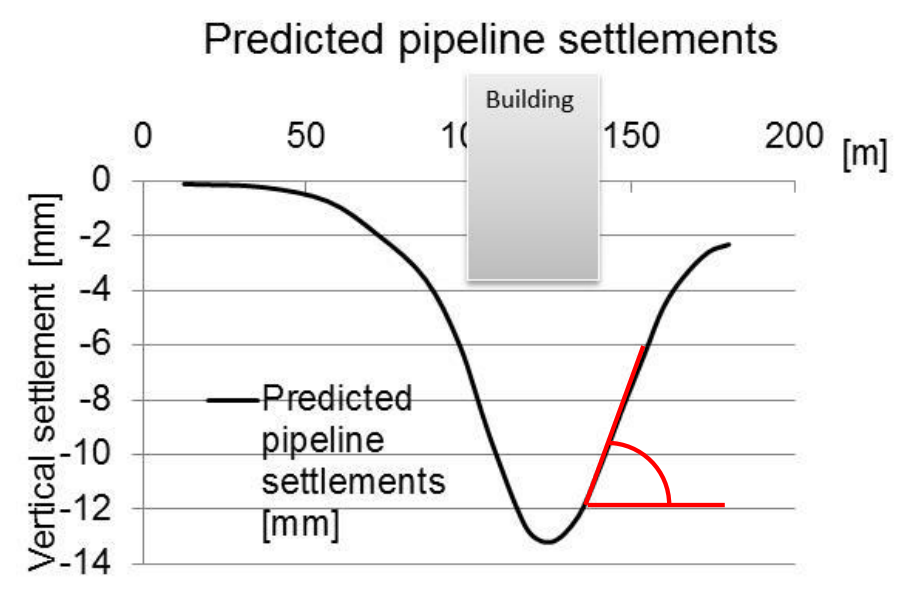

Figure 4 Predicted pipeline settlements after building completion (including structure and service loads). The maximum gradient is plotted in red 


\section{$5 \quad$ Fibre-optic monitoring concept}

In order to validate the modelling and to provide for early warning in the event that settlements exceed the expected values, monitoring of soil compression was requested. The idea was to install a monitoring system capable of locating and quantifying the soil compression below the foundation down to the depth of the water pipeline. Several conditions were set by the nature of the project, such as remote access, distributed compression over depth data and last, but not least, financial constraints. Thus, monitoring by conventional methods seemed unviable. However, a capable method to fulfil these conditions was found to be the distributed fibre-optic sensing technology. The chosen technology, the monitoring concept as well as the monitoring results are described in the next chapter.

\section{Distributed fibre-optic sensing technology}

Distributed fibre-optic strain sensors offer new possibilities in the field of geotechnical monitoring. By integrating a single sensor cable into the soil or structure, an unprecedented amount of accurate, spatially resolved data can be obtained. Current commercially available technology allows for strain measurements in the microstrain $(\mu \varepsilon)$ range $(0.0001 \%)$ with a spatial resolution of $1 \mathrm{~m}$ along a $30 \mathrm{~km}$ long fibre.

A distributed sensing system means that sensor data is continuously (distributed) obtained over a specific distance. This can be idealised as a gapless array of numerous point sensors aligned one after another.

Continuous strain along optical fibres can be measured by several techniques based on the Brillouin scattering effect: spontaneous Brillouin scattering occurs when a light pulse guided through a silica fibre is backscattered by a nonlinear interaction with thermally excited acoustic waves. The scattered light undergoes a frequency shift, which is directly related to the strain and temperature in the medium. Thus, in addition to the strain sensor cable, a loose fibre must be placed for temperature compensation. The backscatter is recorded in the time domain to obtain information of the scattering location along the fibre and the frequency shift of the signal is analysed and converted into strain and temperature data.

When using spontaneous Brillouin scattering, the signal is weak and thus, frequency shift information not very accurate as well as possible distance of signal transfer is limited. In the more refined stimulated Brillouin setup (e.g. Brillouin Optical Time Domain Analysis - BOTDA), two counter-propagating light waves at different frequencies interact via stimulated acoustic waves (Horiguchi \& Tateda 1989). The interaction results in an energy transfer and thus, amplifies the signal, which leads to higher accuracy of the measured strain as well as longer sensor lengths.

BOTDA technology is used in the present monitoring project. With this technology, the strain measured is an average value over the spatial resolution (typically $1 \mathrm{~m}$ ), which corresponds directly to the wavelength of the light pulse sent down the fibre. The measurement accuracy is about 2 to $10 \mu \varepsilon$ and the maximum sensing distance is $>30 \mathrm{~km}$.

\section{Measurement concept: borehole-embedded distributed fibre-optic sensors}

For measuring earth strain, several authors have already suggested and applied fibre-optic sensors embedded into a borehole (e.g. Nöther et al. 2011; Iten 2011; Blum et al. 2008 and Yoshida et al. 2002). For scientific purposes, these systems worked well and provided very useful data. Commercialisation of borehole-embedded distributed fibre-optic sensor measurement systems was started in 2011 by the company Marmota Engineering AG under the name BoreScan. Such BoreScan systems have been applied in the current project.

The concept is that a well-protected fibre-optic cable is inserted into the borehole (see Figure 5). The sensor then needs to be pre-tensioned within the borehole in order to later be able to measure compression. The sensor cable is pre-tensioned against a rod and kept in position within the borehole using additional weight at the bottom. This allows compressive strains of up to 3,000 microstrains to be 
measured. In addition, a temperature sensor is placed in the same borehole. In the next step, a cementbentonite grout of similar stiffness as the surrounding soil was used to backfill the borehole. The grout is intended for the overall bonding between the cable and the soil.

Careful attention should be given to the sensor cable selection, since this is a compromise between stiffness, bonding to grout properties and protection of the fibre inside. The selection significantly impacts the overall system sensitivity: a steel protected cable with a larger diameter might be the best choice in terms of protection. However, such a cable can be very stiff und thus, when settlements occur around the cable, it might be just standing within the ground like a stiff pile. Hence, no strains from the settlements are transferred to the current sensor location; the fibre within the well protected cable. And thus, no or incorrect soil strain is measured by the system.

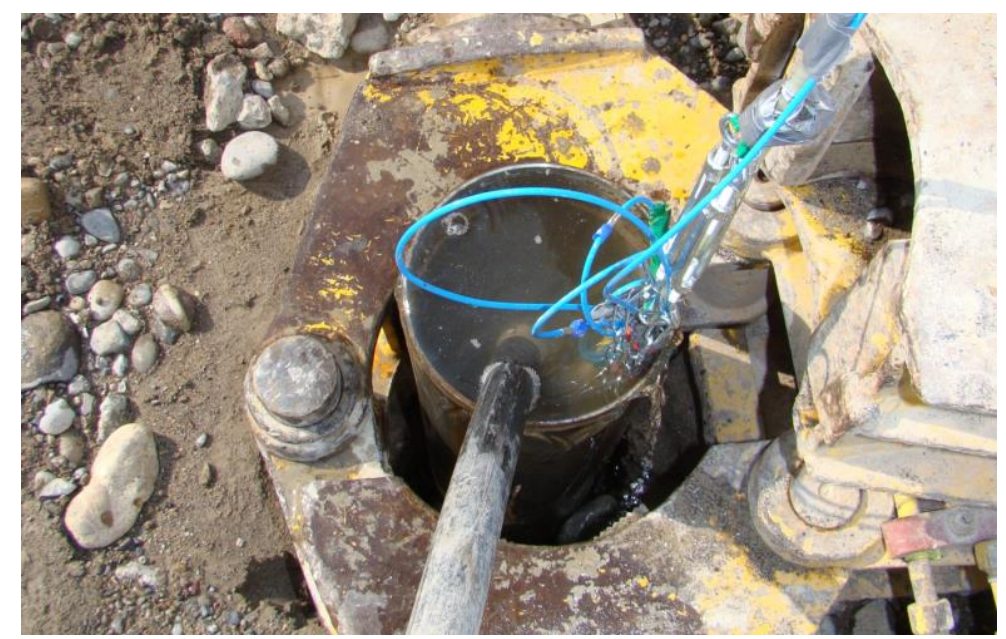

Figure 5 Backfilling the borehole with a cement-bentonite grout after having placed the sensor in the borehole

\section{Instrumentation for the Westlink Project}

Since the main water pipeline is a critical infrastructure of the Zürich Drinkwater Authority (WVZ), an extensive instrumentation was required. The idea was to equip 5 cross-sections with distributed sensors on each side of the pipeline (see Figure 6). The sensors are embedded in up to $18 \mathrm{~m}$ deep boreholes, leading from the foundation level down to the level of the pipeline. Eight boreholes were instrumented with fibre-optic sensors (BoreScan), two boreholes were equipped with USBR settlement probes.

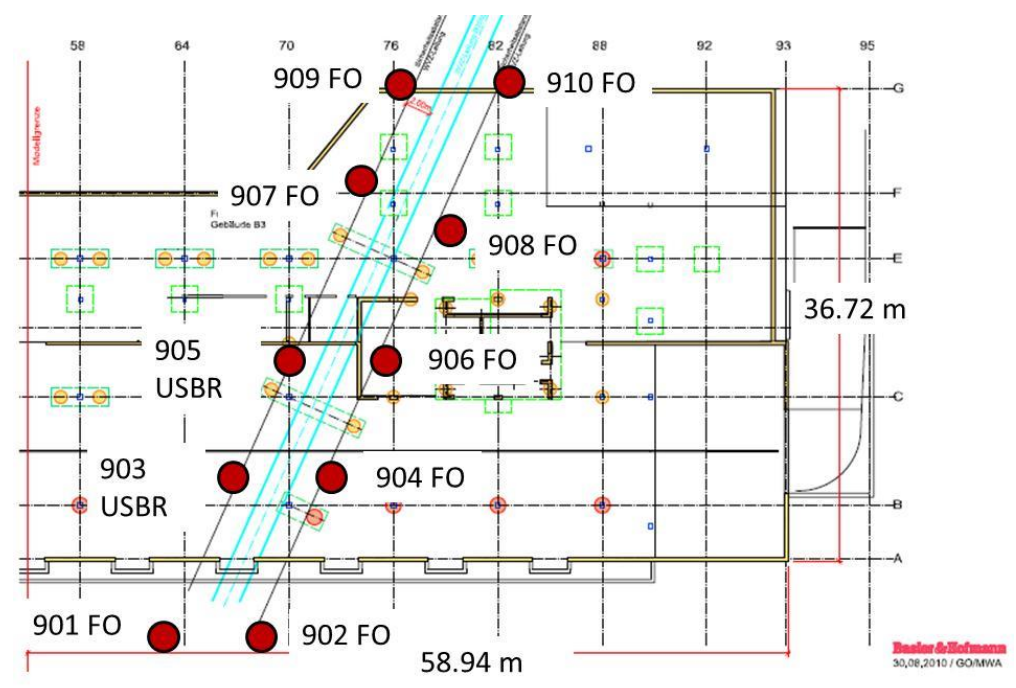

Figure 6 Position of the fibre-optic (FO) and conventional USBR extensometer 
The USBR conventional sensing is carried out by inserting a probe into a tube grouted within the borehole (Clayton et al. 1995). This implies that access to the borehole head is required for every measurement. Sealing this hole in the foundation, which in turn is required for accessing the borehole head, is a critical point.

The Borescan sensors were all cabled to measurement shafts outside the foundation. Thus, no sealing issues appeared and remote sensing is possible. The cabling runs through the foundation (cables are embedded in the concrete - see Figure 7) and was completed about four months after installation of the sensors. At this point, current construction of the building started. Seven of the eight installed sensors survived the heavy earthwork, the driving-in of the sheet pile walls in close proximity and the concrete pouring of the foundation.
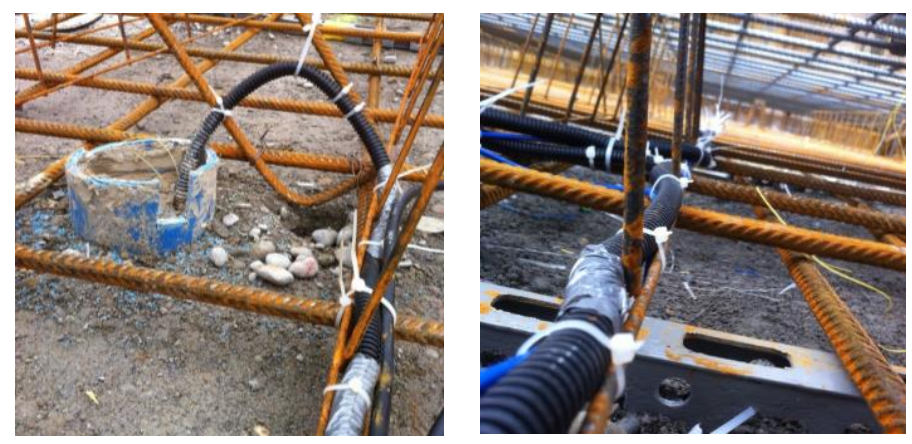

Figure 7 Cabling within the foundation slab with cables attached to the rebars

\section{$9 \quad$ Monitoring}

At the measurement shafts, the sensors are connected to the readout unit for measurement. A single measurement takes about to 2 to $15 \mathrm{~min}$, depending on the desired measurement resolution and accuracy.

The Westlink monitoring program consisted of a zero-measurement and five measurements timed at respective construction stages (see Table 5). Further measurements are planned for the second phase of the Westlink construction 2015.

Table 5 Fibre-optic measurements

\begin{tabular}{ccc}
\hline Measurement & Date & Construction stage \\
\hline 1 & October 2011 & Foundation \\
2 & February 2012 & Ground floor \\
3 & June 2012 & Second floor \\
4 & July 2012 & Third floor \\
5 & August 2012 & Fifth floor \\
\hline
\end{tabular}

\section{$10 \quad$ Monitoring results}

In Figure 8, the results from the monitoring sensor 904 together with USBR settlement probe 903 are shown. The settlements of all measurements/calculations are zeroed at the bottom of the borehole for better comparison. However, one has to be aware that this does not mean that no settlements occur below the borehole depth but they are not measured using this type of installation. The settlements below the bottom of the borehole are not of significant amount as can be seen from the comparison at the borehole top between the geodetically measured settlements and the settlements integrated from the fibre-optic strain measurements. These lower settlements have thus been neglected for the present comparison. The increase of settlements with different building heights and its decrease with depth can be clearly observed. 
The conventional USBR extensometers that were installed in order to validate the fibre-optic sensor readings did not deliver reliable results after the second floor reading (measured settlements ten times higher than those from the geodetic measurements). The two different measurement methods correspond well when comparing it over the whole depth of the borehole. The accuracy and the spatial resolution of the fibre-optic measurements are much higher though.

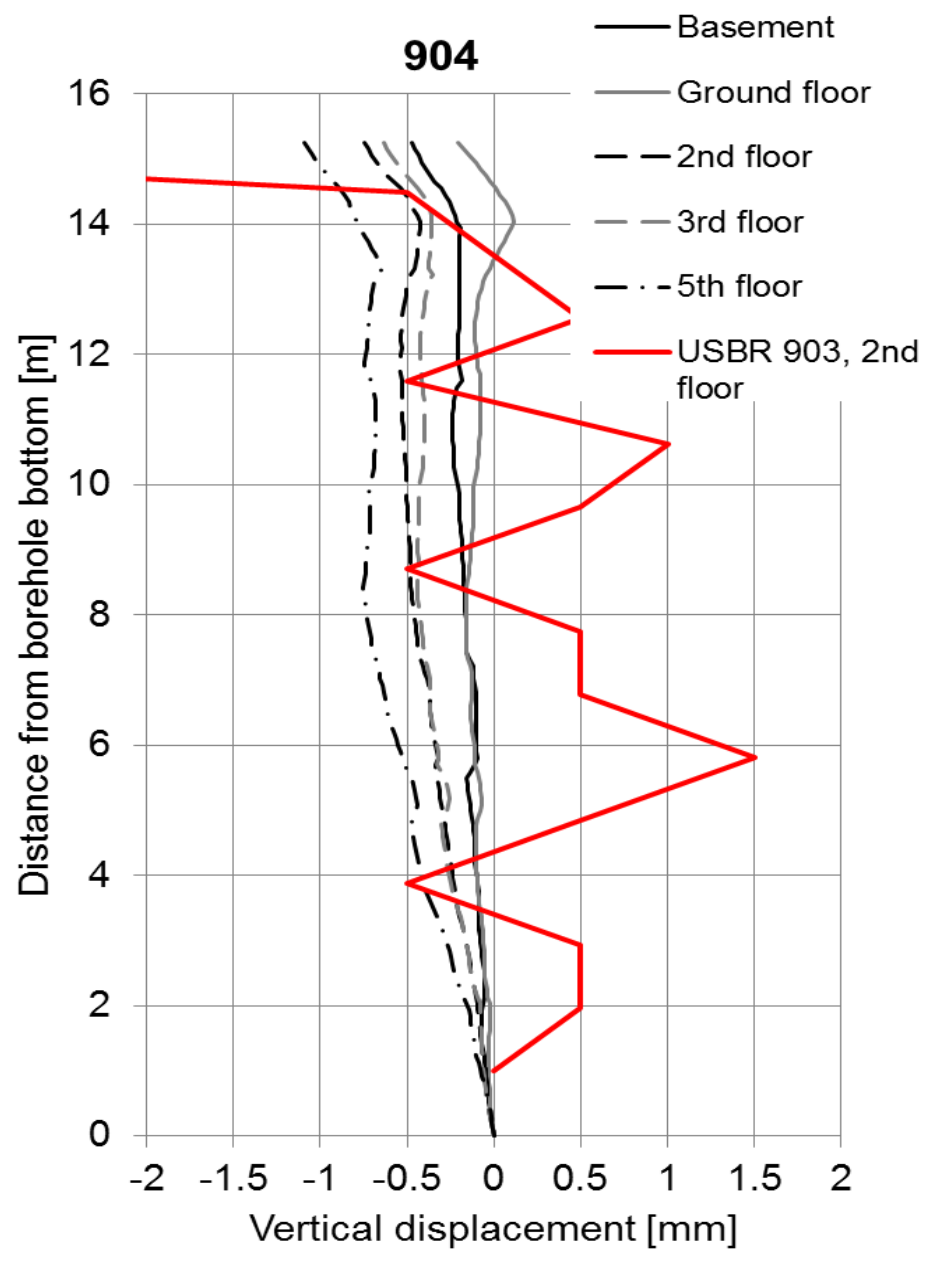

Figure 8 Increase of total settlements due to building construction versus depth. Black = fibreoptic sensor 904. Red = USBR settlement probe 903

\section{Validation of the geotechnical parameters and pipeline safety assessment}

A completely new model is built in the new Program PLAXIS 3D (Brinkgreve et al. 2013) in order to validate the geotechnical parameters adopted for the prediction of settlements.

With this new version of the software, it was possible to model also the pipeline and to determine its displacements.

The last measurement took place after be the completion of the fifth floor. At this stage, the building shell was completed.

In the FE model, only the load due to the building shell is introduced. Compared to the first calculation in the current PLAXIS 3D model the loads are therefore reduced to $65 \%$.

It is observed that the geodetically measured settlements (the lower loading level is taken into account in the new calculation) are considerably lower than predicted, approximately by a factor of four. 
In order to reproduce the same values as the calculated surface settlement in the model, the small strain stiffness of the soil has to be introduced (Table 7). The increasing factor for the elastic shear modulus $E_{0}$ compared to $E_{u r}$ has been chosen equal to 4 . This value is not uncommon for similar soils (Lo Presti et al. 1997). 
Figure 9 shows the settlements versus depth measured with the fibre-optic sensors 902, 904 and 906 . In order to compare measured and calculated settlement, the last ones have to be set to 0 at the bottom end of the borehole. These plotted settlements are relevant for determining the maximum value of the pipeline settlement gradient. Geodetic measurements on the same points showed a total settlement of $5 \mathrm{~mm}$ (Table 6). The measured and the calculated settlements show remarkable good agreement: not only the vertical displacements on the surface, but also the shape of the settlements decrease versus depth correspond well.

Table 6 Settlements measured geodetically at point 904

\begin{tabular}{ccc}
\hline Date & Construction stage & Settlements $(\mathrm{mm})$ \\
\hline October 2011 & Foundation & 0 \\
February 2012 & Ground floor & -1 \\
June 2012 & Second floor & -3 \\
July 2012 & Third floor & -4 \\
August 2012 & Fifth floor & -5 \\
\hline
\end{tabular}

* First measurement. Initial reading carried out after building of the foundation slab.

Table 7 New parameter for the hardening soil small model for the soil at the construction site Westlink

\begin{tabular}{cccccc}
\hline $\begin{array}{c}\text { Soil } \\
\text { (USCS Classification) }\end{array}$ & $\begin{array}{c}\mathbf{E}_{50}{ }^{\text {ref }} \\
\left(\mathbf{M N} / \mathbf{m}^{2}\right)\end{array}$ & $\begin{array}{c}\mathbf{E}_{\text {ur }}{ }^{\text {ref }} \\
\left(\mathbf{M N} / \mathbf{m}^{2}\right)\end{array}$ & $\begin{array}{c}M \\
(-)\end{array}$ & $\begin{array}{c}\mathbf{E}_{0} \\
\left(\mathbf{M N} / \mathbf{m}^{2}\right)\end{array}$ & $\begin{array}{c}\mathbf{g}_{07} \\
(-)\end{array}$ \\
\hline Gravel-Sand (GP-SP) & 80 & 240 & 0.5 & 960 & $1 \times 10^{-4}$ \\
Sand-Clay (SP-SC) & 100 & 300 & 0.5 & 1200 & $1 \times 10^{-4}$ \\
\hline
\end{tabular}

It can also be observed that the difference between measured and calculated displacements increases towards the surface (foundation slab). One possible explanation can be the effect of grout sedimentation: the density of the grout in the uppermost metres seems to be much lower than in the bottom of the borehole, due to the bleeding of the grout suspension. According to the opinion of the authors, the cable is much better embedded in the lower part of the hole, thus in this region the measured settlements are more reliable. 


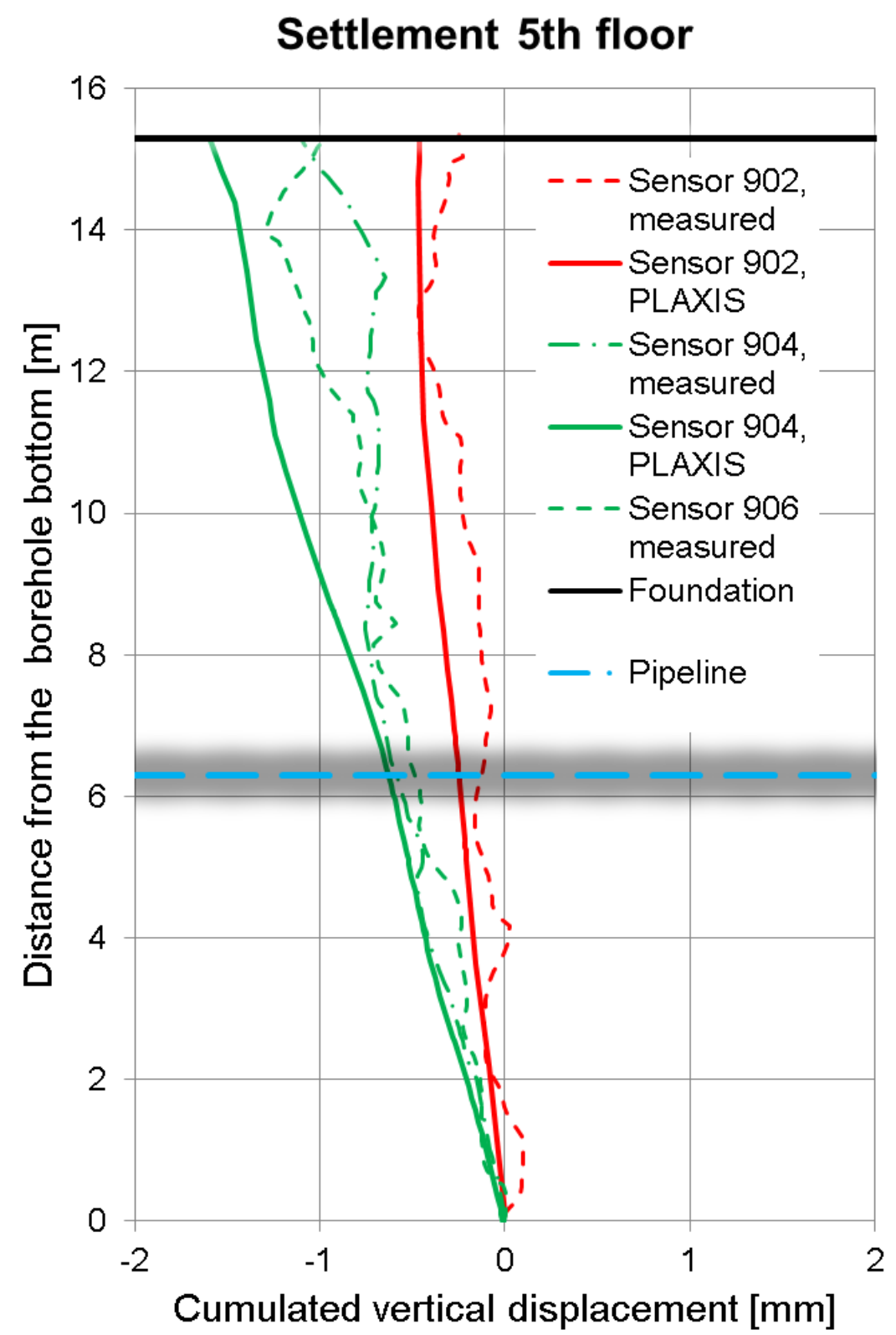

Figure 9 Measured and calculated settlement versus depth. In order to compare measured and calculated settlement, the latter ones are set to $o$ at the bottom end of the fibre-optic cable

Figures 10 and 11 show the building settlements predicted for the fifth floor loading level without (parameter values from Table 3) and with small strain stiffness (parameter values from Table 7) respectively.

The settlement values calculated taking into account the small strain stiffness correspond very well to those obtained with the geodetic measurements. 


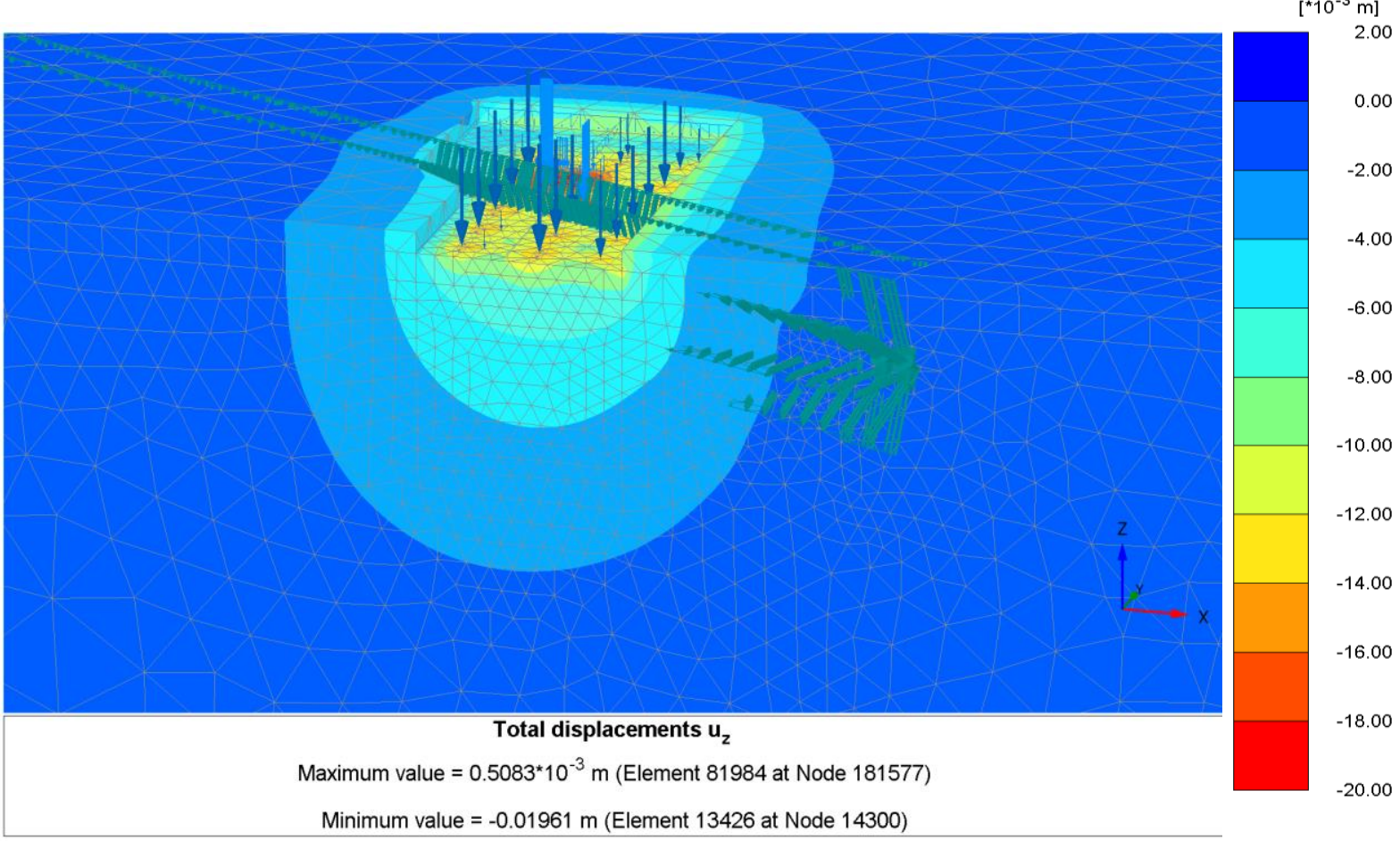

Figure 10 Prediction of building settlement without small strain stiffness

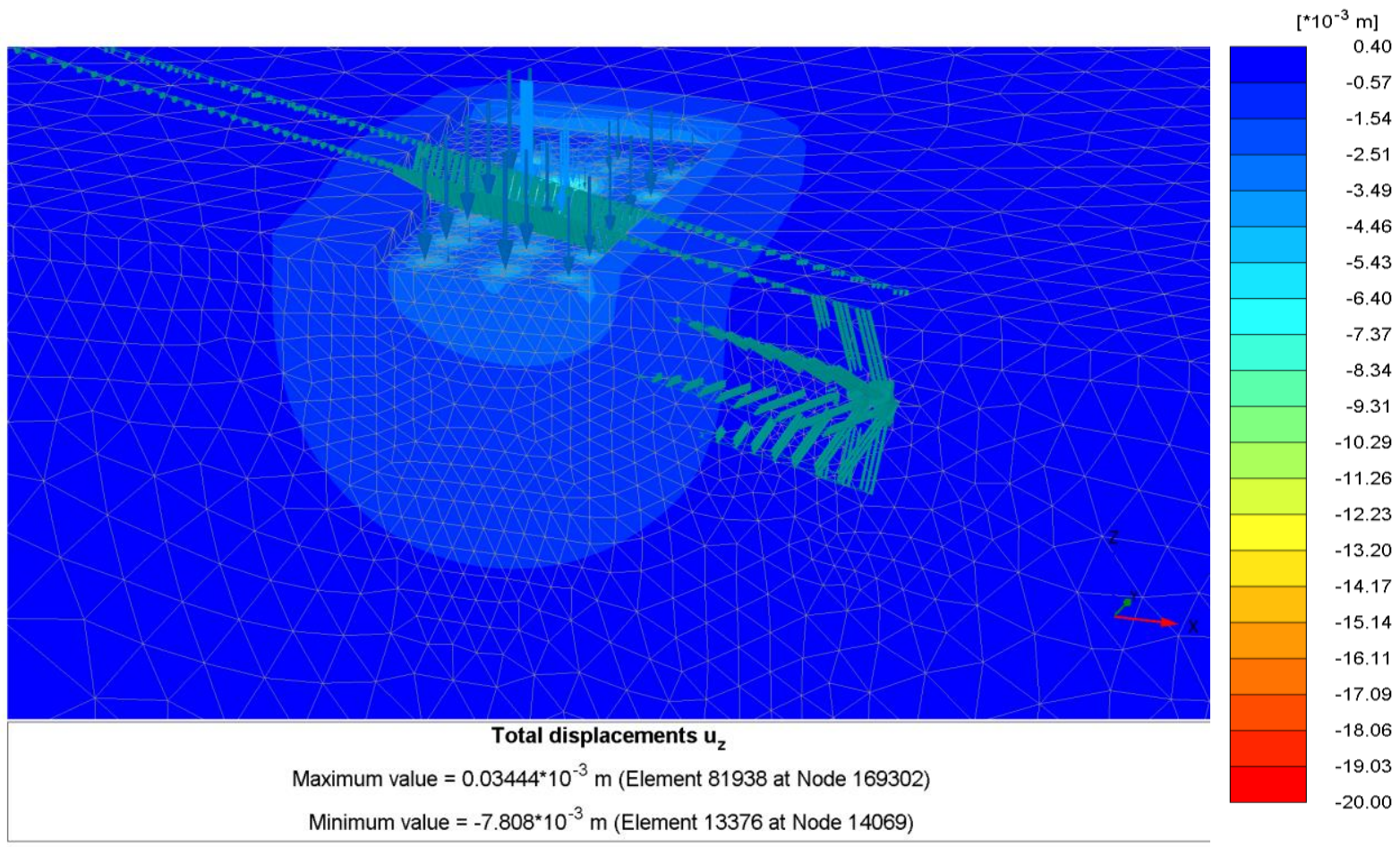

Figure 11 Prediction of building settlement with small strain stiffness

Figures 12 and 13 show the pipeline settlements predicted for the 5th floor loading level without (parameter values from Table 3) and with small strain stiffness (parameter values from Table 6) respectively. 


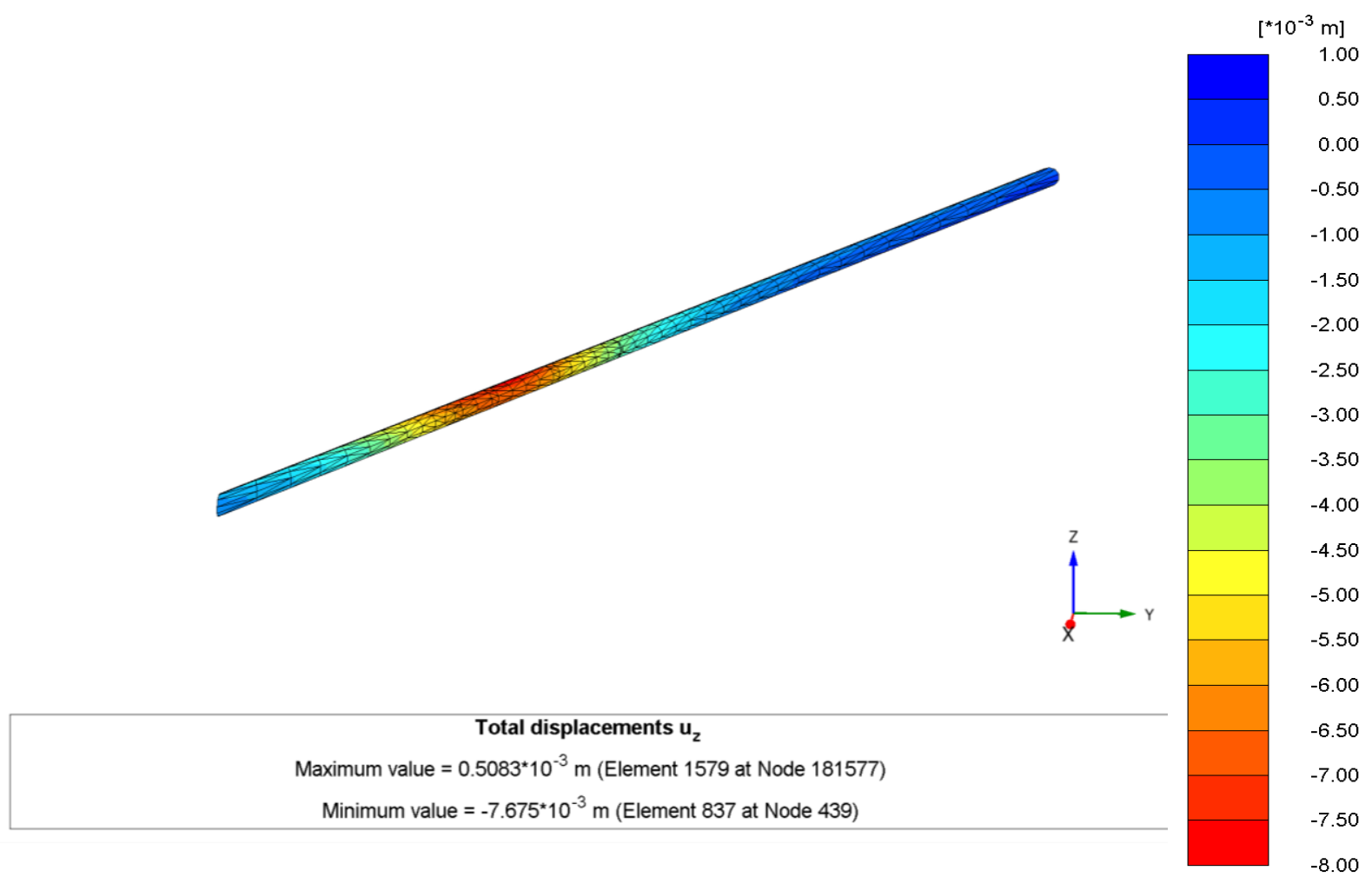

Figure 12 Prediction of pipeline settlements without small strain stiffness

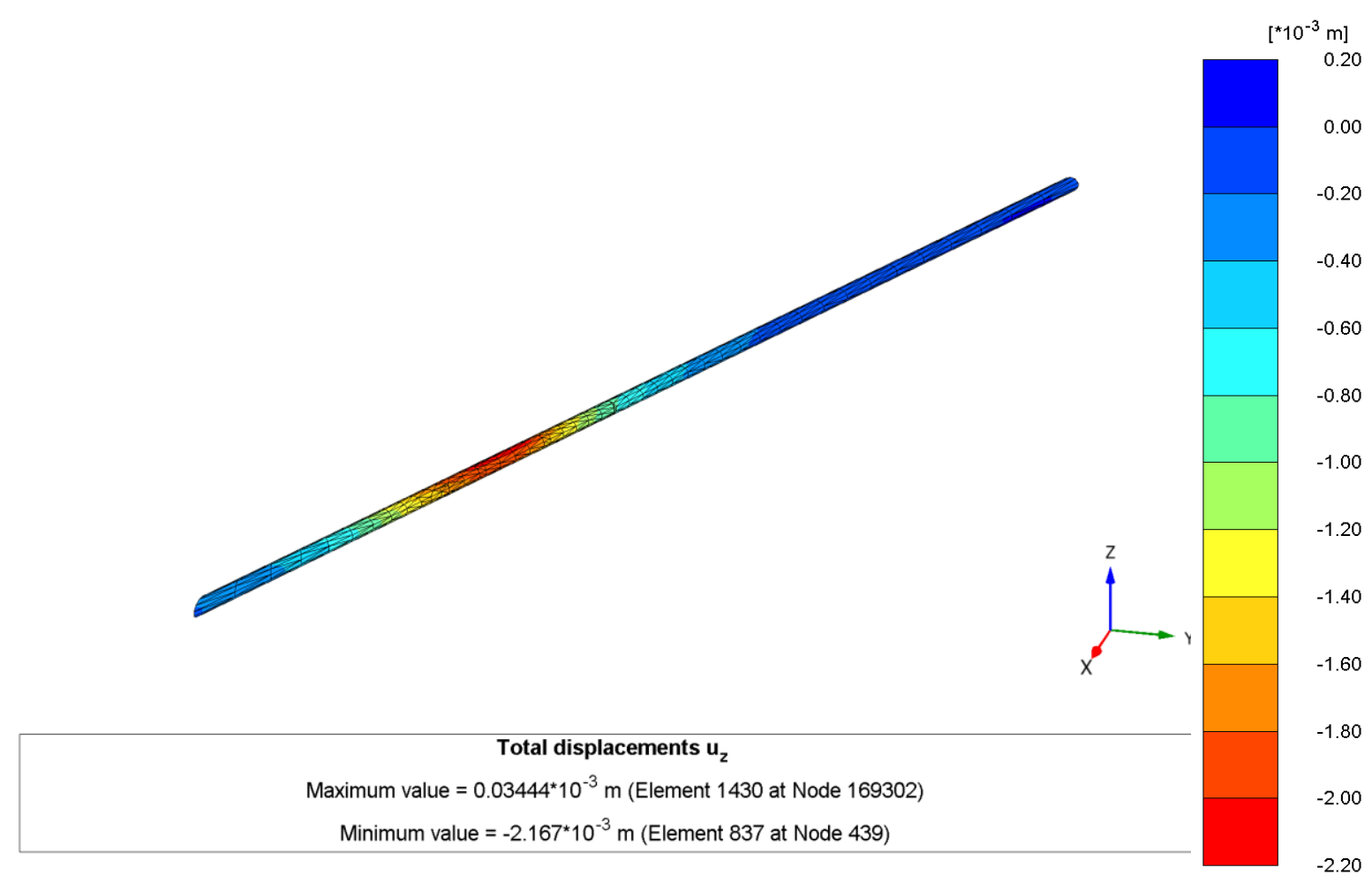

Figure 13 Prediction of pipeline settlement with small strain stiffness

From Figures 12 and 13 it can be observed that the pipeline settlement calculated taking into account the small strain stiffness are approximately 3.5 times smaller than those obtained without small strain stiffness. The current pipeline settlement are also far below the originally estimated values (Figure 14). 
A very important output of the analysis and monitoring is that the current pipeline settlement gradient is far below the predicted current value alarm value (Table 8). Therefore, according to the obtained results, the pipeline safety is not endangered by the construction activities.

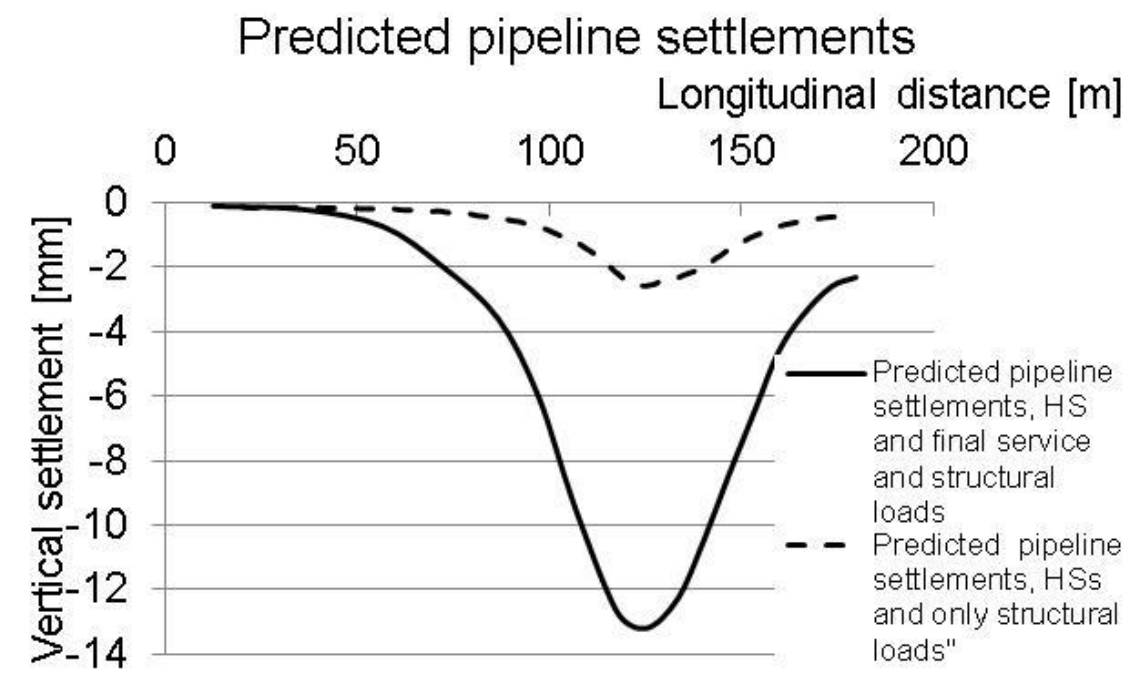

Figure 14 Pipeline settlement predicted for the final loading conditions (PLAXIS ${ }_{3}$ D Foundation, without small strain stiffness) and the current pipeline settlement estimated with small strain stiffness (PLAXIS 3 D 2012)

Table 8 Pipeline settlement gradient (according to fibre-optic measurements) and its alarm value

\begin{tabular}{ccc}
\hline $\begin{array}{c}\text { Gradient of pipeline } \\
\text { settlement }\end{array}$ & $\begin{array}{c}\text { Maximum } \\
\text { gradient (total) }\end{array}$ & $\begin{array}{c}\text { Maximum gradient } \\
\text { (segment) }\end{array}$ \\
\hline Estimated & 0.00012 & 0.000035 \\
Alarm value & & $0.00024^{*}$ \\
\hline
\end{tabular}

* Factor of Safety $=2.0$

\section{Conclusion}

A three-dimensional finite element calculation was carried out in order to assess the impact of the additional loading due to a new building on an existing drinking water pipeline.

Critical values of the gradient of pipeline settlement have been defined based on a finite element calculation of the pipeline structure.

A new state of the art monitoring concept based on fibre-optic measuring technology has been implemented in order to monitor the pipeline safety during construction. The installed distributed fibre-optic sensors produced reliable results which could be validated by geodetic methods. In addition, the obtained data was able to provide a complete and accurate picture of soil displacements down to the pipeline level.

The measured displacements were significantly lower than predicted. A new finite element model with actualised geotechnical parameter values has been implemented. It has been shown that the small strain stiffness of the soil has to be taken into account in order to obtain correct settlement prediction. It can be concluded that the current pipeline safety is not endangered by the carried out construction activities. 


\section{Acknowledgement}

The authors greatly acknowledge the WVZ for their support and for giving the possibility to carry out this extremely interesting investigation, the SBB for the cooperative work and the support and Martin Wallimann (Basler \& Hofmann) who carried out the first Plaxis 3D Foundation calculations that allowed defining the critical gradient settlement of the pipeline.

\section{References}

Benz, T 2007, Small Strain Stiffness and its numerical consequences, PhD thesis, Universität Stuttgart.

Blum, J, Nooner, S \& Zumberge, M 2008, 'Recording earth strain with optical fibers', IEEE Sensors Journal, vol. 8, no. 7, pp. $1152-1160$.

Brinkgreve, RBJ, Broere, W \& Waterman, D 2007, PLAXIS3D foundation user manual, version 2, Delft, Netherlands.

Brinkgreve, RBJ, Engin, E \& Swolfs, WM 2013, PLAXIS3D user manual, Delft, Netherlands.

Burland, JB 1989, 'Small is Beautiful', Canadian Geotechnical Journal, vol. 26, no. 4, pp. 499-516.

Clayton, CR, Matthews, MC \& Simons, NE 1995, Site investigation, 2nd edn, Wiley-Blackwell, Hoboken, New Jersey, USA.

Gysi Leoni Mader AG 2005, Setzungsberechnungen und Überwachungskonzept Schüttung, Parzelle AL 7803, Zürich-Altstetten.

Horiguchi, T \& Tateda, M 1989, 'Optical-fiber-attenuation investigation using stimulated Brillouin scattering between a pulse and a continuous wave', Optics Letters, vol. 14, no. 8, pp. 408-410.

Iten, M 2011, Novel applications of distributed fiber-optic sensing in geotechnical engineering, PhD thesis, ETH Zürich.

Jäckli Geologie 2008, Geologische Baugrunduntersuchungen Überbauung WestLink, Zürich.

Lo Presti, DCF, Jamiolkowski, M, Pallara, O, Cavallaro, A \& Pedroni, S 1997, 'Shear modulus and damping of soils', Geotechnique, vol. 47, no. 3, pp. 603-617.

Nöther, N, Krcmar, M, von der Mark, S, Henninges, J \& Reinsch, T 2011, 'Application of distributed optical fiber sensors to borehole temperature and strain monitoring', Proceedings of the SENSOR+TEST Conferences, AMA Service GmbH, Wunstorf, Germany, pp. 874-877.

Schanz, T, Vermeer, PA \& Bonnier, PG 1999, 'The hardening soil model: formulation and verification', Proceedings of the 1st International PLAXIS Symposium: Beyond 2000 in computational geotechnics, Balkema, Rotterdam, $16 \mathrm{p}$.

Yoshida, Y, Kashiwai, Y, Murakami, E, Ishida, S \& Hashiguchi, N 2002, 'Development of the monitoring system for slope deformations with fiber bragg grating arrays', Proceedings of SPIE 1694, Smart Structures and Materials 2002, Smart Sensor Technology and Measurement Systems, vol. 296. 